\title{
Venous thromboembolism in the ICU: main characteristics, diagnosis and thromboprophylaxis
}

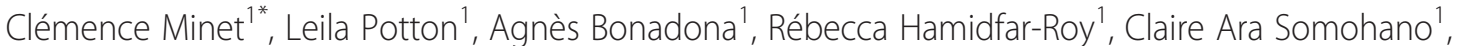 \\ Maxime Lugosi ${ }^{1}$, Jean-Charles Cartier ${ }^{1}$, Gilbert Ferretti ${ }^{2,3}$, Carole Schwebel ${ }^{1}$ and Jean-François Timsit ${ }^{1,3}$
}

\begin{abstract}
Venous thromboembolism (VTE), including pulmonary embolism (PE) and deep venous thrombosis (DVT), is a common and severe complication of critical illness. Although well documented in the general population, the prevalence of PE is less known in the ICU, where it is more difficult to diagnose and to treat. Critically ill patients are at high risk of VTE because they combine both general risk factors together with specific ICU risk factors of VTE, like sedation, immobilization, vasopressors or central venous catheter. Compression ultrasonography and computed tomography (CT) scan are the primary tools to diagnose DVT and PE, respectively, in the ICU. CT scan, as well as transesophageal echography, are good for evaluating the severity of PE. Thromboprophylaxis is needed in all ICU patients, mainly with low molecular weight heparin, such as fragmine, which can be used even in cases of non-severe renal failure. Mechanical thromboprophylaxis has to be used if anticoagulation is not possible. Nevertheless, VTE can occur despite well-conducted thromboprophylaxis.
\end{abstract}

\section{Introduction}

A 77-year-old man was admitted to the ICU as a result of status epilepticus. He was mechanically ventilated for 3 days, and received 5,000 UI unfractionated heparin (UFH) daily as thromboprophylaxis. The day after his extubation, he became hypoxemic without hypotension. A contrast enhanced computed tomography (CT) scan of the chest (Fig. 1) showed a proximal bilateral pulmonary embolism from the lobar to subsegmental arteries of both sides. Transthoracic echocardiography and CT scan did not show any signs suggestive of right ventricular

\footnotetext{
* Correspondence: CMinet@chu-grenoble.fr

'UJF-Grenoble I, University Hospital Albert Michallon, Medical Intensive Care Unit, Grenoble F-38041, France

Full list of author information is available at the end of the article
}

strain. He recovered with a therapeutic dose of heparin, and was discharged home 1 week later. This clinical case shows that clinical presentation of proximal pulmonary embolism is not typical in mechanical ventilated patients and can occur under thromboprophylaxis.

Venous thromboembolism (VTE), including deep venous thrombosis (DVT) and pulmonary embolism (PE), is a common complication in the ICU. Critically ill patients are at high risk of VTE as they are susceptible to both general risks factors of VTE as well as those specific to ICU patients, such as sedation, immobilization, and vasopressors. The prevalence of VTE, and especially of PE, is underestimated in the ICU, as it is often clinically silent, especially in sedated and mechanically ventilated patients. ICU-acquired thromboembolic events are difficult to diagnose, as they may mimic many other diseases.

Our purpose was to conduct a review of the most relevant published clinical studies on ICU-acquired VTE in order to highlight the main characteristics and the current strategies for the diagnosis and prevention of this disease.

\section{Search strategy}

A search on the PubMed database for English language publications between 1981 and 2014 was performed using search terms "VTE in ICU", "risk factors of VTE in ICU", "thromboprophylaxis in ICU", "pulmonary embolism in ICU", "deep venous thrombosis in ICU", "mechanical thromboprophylaxis", "diagnosis of pulmonary embolism in ICU".

\section{Epidemiology}

PE is one of the three most frequently underdiagnosed illnesses identified during autopsies [1]. Autopsy studies detected PE in 7 to $27 \%$ of critically ill patients; of these, only one-third were clinically suspected [2].

When PE is clinically suspected, there are three categories of risk: high-risk patients, who are hemodynamically 


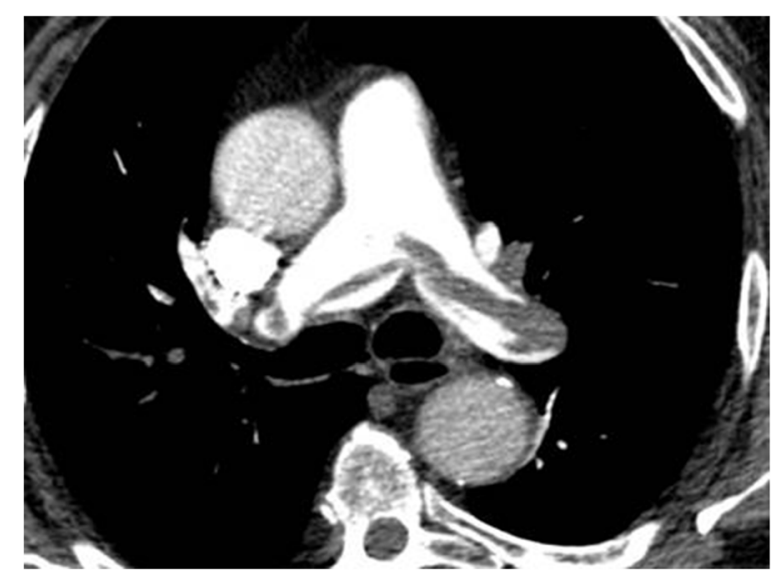

Fig. 1 Proximal bilateral pulmonary embolism on computed tomography scan in a mechanically ventilated ICU patient

unstable with shock or hypotension; intermediate- to high-risk patients, who are normotensive with a Pulmonary Embolism Severity Index (PESI) $\geq$ III or a simplified (s)PESI $\geq 1$ and in whom there is right ventricular failure or a rise of cardiac biomarkers; and low risk patients, who have a PESI of class I or II, or a sPESI of 0 [3]. Studies on VTE in the ICU predominantly focus on DVT. The incidence of DVT ranges from 5 to $31 \%$ according to the case-mix and the diagnosis methods used [4-10] (Tables 1 and 2).

In a medical-surgical ICU, when compression ultrasonography (CUS) was performed, the incidence of DVT ranged from 10 to $100 \%$ in patients with no clinical suspicion of DVT [11, 12]. Among patients with trauma, routine CT scans discovered asymptomatic PE in $24 \%$ of patients [13].

The prevalence and incidence of PE in the ICU remain unclear. Three recent prospective studies have investigated the incidence of PE in the ICU. A PE was clinically suspected in 0.4 to $2.3 \%$ of medical ICU patients $[14,15]$; the incidence rose to $3.2 \%$ in post-traumatic ICU patients [16], although most patients had thromboprophylaxis. In the PROTECT trial comparing prophylaxis with dalteparin versus UFH in critically ill patients
(90\% mechanically ventilated), a clinically suspected PE was diagnosed in $1.3 \%$ and $2.3 \%$ of patients, respectively [8].

In 176 consecutive mechanically ventilated patients requiring a CT scan for any medical reason, we applied a standard imaging protocol to detect PE [17]. PE was diagnosed in $33(18.7 \%)$ patients, and was clinically silent in $20(60 \%)$ of these [17]. CUS was performed within 48 hours of the CT scan and detected DVT associated with PE in 11 (33\%) patients. Thirty-five (19.9\%) of the 176 patients had a diagnosis of DVT, despite pharmacological thromboprophylaxis or anticoagulant treatment administered to $92(52.2 \%)$ of them.

$\mathrm{PE}$ is associated with a high mortality rate, especially when it is associated with right ventricular failure or shock [18]. Mortality in untreated PE is approximately $30 \%$, but with adequate (anticoagulant) treatment, this can be reduced to 2 to $8 \%$ [19].

\section{Diagnosis of ICU-acquired venous thromboembolism}

DVT can be ruled out in an outpatient who is judged clinically unlikely to have it and who has a negative Ddimer test [20]. But D-dimer levels can rise in some pathologies like atrial fibrillation, acute coronary syndromes, stroke, acute upper gastrointestinal hemorrhage, infection, disseminated intravascular coagulation, and severe renal dysfunction, which are frequent in critically ill patients. As such, D-dimer levels have low specificity in the ICU [21]. Crowther et al. [22] have shown that neither hypercoagulability nor D-dimer levels predict critically ill patients at risk of DVT and should thus not be used as a diagnostic test for it.

In the general population, CUS is now the first choice to diagnose DVT with high sensitivity and specificity [23]. Outpatients with symptoms of DVT and two consecutively negative CUS exams within 7 days have less than $1 \%$ risk to develop DVT, suggesting that CUS is accurate for ruling out clinically important DVT [24]. DVT can be excluded based on a negative single proximal CUS in patients with low and intermediate clinical probability of DVT [25]. In critically ill patients, an

Table 1 Rate of deep venous thrombosis in critically ill patients without thromboprophylaxis (control groups in randomized clinical trials versus groups with thromboprophylaxis)

\begin{tabular}{|c|c|c|c|c|c|}
\hline Study & Study design & Population & DVT screening method & Number of patients & $\mathrm{DVT}(\%)$ \\
\hline Moser et al. 1981 [4] & Prospective cohort & Respiratory ICU & $\begin{array}{l}\text { I-labeled fibrinogen leg scanning } \\
\text { for 3-6 days }\end{array}$ & 23 & 13 \\
\hline Cade $1982[5]$ & Blinded RCT & General ICU patients & $\begin{array}{l}\text { 125l-labeled fibrinogen leg scanning } \\
\text { for 4-10 days }\end{array}$ & 59 & 29 \\
\hline Kapoor et al. 1999 [6] & Blinded RCT & Medical ICU patients & CUS at admission and every 3 days & 390 & 31 \\
\hline Fraisse et al. 2000 [7] & Blinded RCT & $\begin{array}{l}\text { Exacerbated COPD patients with } \\
\text { mechanical ventilation }>48 \text { hours }\end{array}$ & $\begin{array}{l}\text { CUS (weekly) and venography } \\
\text { (before day 21) }\end{array}$ & 85 & 28 \\
\hline
\end{tabular}


Table 2 Rates of deep vein thrombosis in critically ill patients with thromboprophylaxis

\begin{tabular}{|c|c|c|c|c|c|c|}
\hline Author (Year) & Study design & Population & DVT screening method & Thromboprophylaxis & $\begin{array}{l}\text { Number } \\
\text { of patients }\end{array}$ & DVT (\%) \\
\hline Ibrahim et al. 2002 [10] & Prospective study & $\begin{array}{l}\text { Medical ICU patients; } \\
\text { MV >7 days }\end{array}$ & Serial CUS (weekly) & $\begin{array}{l}\text { Twice daily SC UFH } \\
5,000 \mathrm{UI}\end{array}$ & 110 & 23.6 \\
\hline Cook et al. 2005 [9] & Prospective study & Medical-surgical ICU & $\begin{array}{l}\text { CUS } 48 \text { hours after admission, } \\
\text { twice weekly and in case of clinical } \\
\text { suspicion }\end{array}$ & $\begin{array}{l}\text { Twice daily SC UFH } \\
5,000 \mathrm{UI}\end{array}$ & 261 & 9.6 \\
\hline PROTECT 2011 [8] & Blinded RCT & Medical-surgical ICU & $\begin{array}{l}\text { CUS } 48 \text { hours after admission, } \\
\text { twice weekly and in case of clinical } \\
\text { suspicion }\end{array}$ & $\begin{array}{l}\text { SC UFH 5,000 UI/ } \\
\text { dalteparin 5,000 UI } \\
\text { plus placebo }\end{array}$ & 3,764 & 5.4 \\
\hline
\end{tabular}

CUS compression ultrasonography; DVT deep vein thrombosis; MV mechanical ventilation; RCT randomized clinical trial; SC subcutaneous; UFH unfractionated heparin

accurate diagnosis of proximal lower extremity DVT can be achieved by intensivists performing lower limb CUS at the bedside, with a sensitivity of $85 \%$ and a specificity of $96 \%$ [26].

A chest CT-based approach has now replaced the gold standard pulmonary angiography with equivalent clinical validity to rule out PE [27]. CT pulmonary angiography (CTPA) has become the imaging reference exam to diagnose PE in the ICU. Multi-detector CT angiography at $1.25 \mathrm{~mm}$ collimation thickness is the most sensitive and allows better imaging of segmental and sub-segmental pulmonary arteries [28]. In cases where PE is suspected, multi-detector CT angiography sensitivity ranged between 83 and $100 \%$, and its specificity ranged between 89 and $97 \%$ [29], although this study did not provide specific data for the ICU population. CT scans can also be useful for determining the severity of acute pulmonary embolisms, by evaluating right ventricular dysfunction, which is well correlated with echocardiography findings [30, 31].

As CTPA requires patients to be transported to the radiology department and in a rather stable state, it cannot be performed in all ICU patients with a clinical suspicion of PE. Moreover, intra-hospital transport may have a negative impact on ventilated critically ill patients [32]. This explains the delayed use of such definitive diagnostic tests in the ICU. Most epidemiologic studies have to be interpreted with caution, as the diagnosis of $\mathrm{PE}$ is often based on questionable definitions. We identified only two prospective studies evaluating the rate of $\mathrm{PE}$ in critically ill patients with a standardized protocol of CT scans performed in a homogenous consecutive population: one in severe injured trauma patients (24\% PE when scanning asymptomatic severe injured patients) [13]; and one in mechanically ventilated patients $(18.7 \%$ $\mathrm{PE}$ using a standard imaging protocol to detect PE during CT scan for any other medical reason) [17].

Transthoracic echocardiography (TTE) could be helpful in the diagnosis of PE at the bedside by looking for right ventricular hypokinesis, increases in right ventricular end-diastolic diameter, or tricuspid regurgitation velocity. Miniati et al. [33] showed that TTE could help to assess the physiological effects of PE but that it fails to identify more than $50 \%$ of PE proven on pulmonary angiography. TTE requires better sensitivity for it to be used as a screening test to rule out PE.

Transesophageal echocardiography (TEE) could be useful in PE diagnosis, particularly in hemodynamically unstable patients who have predominantly bilateral central PE. This exam is non-invasive, can be done at the bedside, identifies clots and, compared with CT scanning, has very good sensitivity and specificity ( $80 \%$ and 100 \%, respectively, in Pruszczyk et al.'s study [34]). But TEE has a higher failure rate than CT scans for diagnosis of distal PE.

\section{Venous thromboembolism risk factors more specific to critically ill patients}

ICU patients share similar general risk factors for VTE with other patients: age, immobilization, obesity, past history of personal or familial VTE, past history of neoplasm, sepsis, stroke, respiratory or heart failure, pregnancy, trauma, or recent surgery $[9,17,35-37]$.

Additional, specific risk factors for the ICU population have also been described [35, 38] (Table 3).

Mechanical ventilation, by decreasing venous return and requiring sedation (and immobilization) increases the risk of VTE. Although critically ill patients with DVT had a longer duration of mechanical ventilation than those who did not [9], the causal relationship between length of mechanical ventilation and VTE is unclear [17]. Sedation is not an independent risk factor in itself.

Central venous catheterization is another important risk factor for ICU-acquired VTE [39], especially when inserted in femoral veins $[38,40]$, with a catheter-related thrombosis occurrence rate ranging from $2.2 \%$ [8] up to 69 \% [17]. Catheter-related thrombosis was originally described by Chastre et al. [41]. The incidence of thrombosis is 2 to $10 \%$ with subclavian catheter $[39,40]$ but may reach 10 to $69 \%$ with femoral catheter [17, 40, 42, 43 ] and 40 to $56 \%$ with internal jugular catheter. In 
Table 3 Venous thromboembolism risk factors

\begin{tabular}{ll}
\hline General VTE risk factors & ICU-acquired VTE risk factor \\
\hline Age & Sepsis \\
Past history of VTE & Vasopressor use \\
Past history of cancer & Respiratory or cardiac failure \\
Immobilization & Pharmacologic sedation \\
Obesity & Mechanical ventilation \\
Pregnancy & Central venous catheter \\
Trauma, spinal cord injury & End-stage renal failure \\
Recent surgery & \\
Stroke & \\
\hline
\end{tabular}

VTE venous thromboembolism

superior vena cava catheter-related thrombosis, the risk of associated PE is 7 to $17 \%[44,45]$. Lower-limb DVT was associated with a four-fold increase in the risk of PE [17], whereas upper-limb DVT was not a significant risk factor for PE [46-48]. Catheter-related thrombosis risk increases with the duration of catheter placement [10]. In the ICU, catheter-related thrombosis is more frequent in older patients, with femoral catheters, when catheters are inserted in an emergency situation, and in patients not receiving therapeutic heparin $[39,40]$. Sepsis may induce procoagulant status and favor catheter-related thrombosis. Catheter-related sepsis is often associated with catheter-related thrombosis [49], and also in ICU patients [39].

Vasopressor administration was found to be an independent risk factor for DVT (hazard ratio 2.8, $95 \%$ confidence interval 1.1 to 7.2) [9], certainly explained by reduced absorption of subcutaneous heparin linked to the vasoconstriction of peripheral blood vessels. This mechanism could explain the lower anti-Xa factor activity after thromboprophylaxis with low molecular weight heparin (LMWH) in critically ill patients on vasopressors [50].

Platelet transfusion (hazard ratio 3.2, $95 \%$ confidence interval 1.2 to 8.4) [9] and high levels of platelets (odds ratio $1.003,95 \%$ confidence interval 1.000 to 1.006 ) [17] have been identified as risk factors for VTE, certainly related to increased platelet activation and adherence to vessel walls with subsequent fibrin clot formation, as described in inflammatory processes and sepsis [51].

The level of risk of VTE in critically ill patients also depends on the underlying illness leading to ICU admission [52].

\section{Is there a rationale to use thromboprophylaxis in critically ill patients?}

Thromboprophylaxis is recommended in the general surgical [53] and medical [54] populations. In the ICU, three randomized controlled trials (RCTs), comparing thromboprophylaxis with placebo using objective screening for DVT [5-7] (Table 4), found that the rate of DVT was significantly lower in the thromboprophylaxis group regardless of the thromboprophylaxis used, UFH $[5,6]$ or LMWH [7]. The American College of Chest Physicians (ACCP) recommends thromboprophylaxis for prevention of VTE in critical care patients (grade Ia: strong recommendation with high quality of evidence) $[35,55]$. Moreover, omission of thromboprophylaxis within the first 24 hours of ICU admission without obvious reasons is associated with a higher risk of mortality in the ICU [56].

In the ICU, up to $80 \%$ of patients under thromboprophylaxis have at least one episode of bleeding, more often minor [57]. Major bleeding is described in $5.6 \%$ of critically ill patients with or without preventive anticoagulation [57], and up to $7.2 \%$ when dalteparin is used in severe renal insufficiency patients [58].

\section{Which thromboprophylaxis for which patients in the ICU?}

\section{Unfractionated heparin versus low molecular weight} heparin

In general surgical patients [59] and medically ill inpatients [60], LMWH and UFH have similar efficacy and safety. In patients with major trauma, enoxaparin (LMWH) was more effective than subcutaneous UFH [61]. In patients with heart failure or severe respiratory disease, enoxaparin $40 \mathrm{mg}$ once daily was as effective as 5,000 UI UFH three times daily for prevention of thromboembolic events [62].

Until now, the PROTECT study [8] is the only RCT to have compared UFH with LMWH as VTE prophylaxis in the ICU, excluding patients at very high risk of bleeding. Overall, 3,764 patients, including $90 \%$ mechanically ventilated patients, were randomly allocated to receive 5,000 UI subcutaneous dalteparin once daily plus placebo once daily, or 5,000 UI subcutaneous UFH twice daily. DVT was screened for using CUS within 48 hours after admission, and then twice weekly or in case of clinical suspicion. There was no significant difference in proximal DVT: $5.1 \%$ DVT in the dalteparin group versus $5.8 \%$ in the UFH group $(P=0.57)$. However, the rate of $\mathrm{PE}$ was significantly lower in the dalteparin group (1.3\%) compared with the UFH group $(2.3 \%)(P=0.01)$.

A recent review described a significant reduction in PE, but not DVT, with LMWH compared with UFH, with a similar rate of bleeding [63]. ACCP recommends the use of LMWH or UFH thromboprophylaxis in critical care patients at moderate risk for VTE and LMWH for critical care patients at higher risk (major trauma or orthopedic surgery patients) (grade Ia) [35, 55]. 
Table 4 Thromboprophylaxis in ICU (blinded randomized controlled trials)

\begin{tabular}{|c|c|c|c|c|c|c|c|c|c|c|c|}
\hline \multirow[b]{2}{*}{ Author (Year) } & \multirow[b]{2}{*}{ Population } & \multirow[b]{2}{*}{$\begin{array}{l}\text { Number of } \\
\text { patients }\end{array}$} & \multirow[b]{2}{*}{ Diagnosis method } & \multirow[b]{2}{*}{ Control } & \multirow[b]{2}{*}{ Intervention } & \multicolumn{3}{|l|}{ DVT (\%) } & \multicolumn{3}{|l|}{ PE (\%) } \\
\hline & & & & & & Control & Intervention & $P$-value & Control & Intervention & $P$-value \\
\hline Cade 1982 [5] & $\begin{array}{l}\text { General ICU } \\
\text { patients }\end{array}$ & 119 & $\begin{array}{l}\text { 125I-labeled } \\
\text { fibrinogen leg } \\
\text { scanning for 4-10 } \\
\text { days }\end{array}$ & Placebo & $\begin{array}{l}\text { UFH 5,000 UI SC } \\
\text { twice daily }\end{array}$ & NR/NR (29\%) & NR/NR (13 \%) & $<0.05$ & & & \\
\hline Kapoor et al. 1999 [6] & $\begin{array}{l}\text { Medical ICU } \\
\text { patients }\end{array}$ & 791 & $\begin{array}{l}\text { CUS at admission and } \\
\text { every } 3 \text { days }\end{array}$ & Placebo & $\begin{array}{l}\text { UFH 5,000 UI SC } \\
\text { twice daily }\end{array}$ & 122/390 (31 \%) & 44/401 (11\%) & 0.001 & & & \\
\hline Fraisse et al. 2000 [7] & $\begin{array}{l}\text { Exacerbated COPD } \\
\text { patients with MV } \\
>48 \text { hours }\end{array}$ & 223 & $\begin{array}{l}\text { CUS weekly and } \\
\text { venography before } \\
\text { day } 21\end{array}$ & Placebo & $\begin{array}{l}\text { Nadroparin } 70 \\
\text { Ul anti-factor } \\
\text { Xa/kg once } \\
\text { daily }\end{array}$ & 24/85 (28 \%) & 13/84 (15.5 \%) & $<0.045$ & & & \\
\hline PROTECT 2011 [8] & $\begin{array}{l}\text { Medico-surgical } \\
\text { ICU patients }\end{array}$ & 3764 & $\begin{array}{l}\text { CUS at admission, } \\
\text { twice weekly, and in } \\
\text { case of clinical } \\
\text { suspicion }\end{array}$ & $\begin{array}{l}5,000 \text { UI SC } \\
\text { UFH twice } \\
\text { daily }\end{array}$ & $\begin{array}{l}\text { Dalteparin } 5,000 \\
\text { UI SC once daily } \\
\text { plus placebo }\end{array}$ & 96/1,873 (5.1\%) & 109/1,873 (5.8 \%) & 0.57 & 43/1,873 (2.3 \%) & 24/1,873 (1.3 \%) & 0.01 \\
\hline
\end{tabular}

COPD chronic obstructive pulmonary disease; CUS, compression ultrasonography; DVT deep vein thrombosis; MV mechanical ventilation; NR not reported; $P E$ pulmonary embolism; SC subcutaneous; UFH unfractionated heparin 


\section{Are low molecular weight heparins easy to use in critically ill patients?}

Anti-factor Xa level is a clinically practicable marker of LWMH anticoagulant effectiveness; levels of 0.1 to 0.3 $\mathrm{UI} / \mathrm{ml}$ are considered as effective antithrombotic activity. There is no need to systematically measure anti-factor Xa levels for each patient but it could be useful in some populations such as critically ill patients because possible patient-dependent factors can influence plasma antifactor Xa activity, like decreased bioavailability because of edema, vasoconstrictive treatment or renal failure.

Lower anti-factor Xa levels in blood have been reported in ICU patients with generalized edema [64] or receiving vasopressors [50, 65]. This can be explained by impaired peripheral circulation. The systemic bioavailability of the anticoagulant may then be inadequate. However, Priglinger et al. [65] did not show any correlation between dose of norepinephrine and anti-factor Xa blood levels. Robinson et al. [66] conducted a RCT showing that an increase in enoxaparin dose led to significantly increased anti-factor Xa activity but a ceiling effect seems to exist at the dose of $60 \mathrm{mg} /$ day [66]. Mayr et al. also reported an anti-factor Xa activity below the recommended level $(0.1$ to $0.3 \mathrm{UI} / \mathrm{ml})$ in ICU patients; it was significantly correlated to multiple organ dysfunction as well as to a high body weight [67].

These results suggest that an inadequate dose of enoxaparin can fail to prevent VTE in critically ill patients. Its efficacy should be controlled by monitoring the antifactor Xa activity in each ICU patient, regardless of the patient's renal function.

\section{Low molecular weight heparins and renal insufficiency in critically ill patients}

LMWHs are more dependent on renal clearance than UFHs and could bioaccumulate in patients with renal insufficiency, causing more bleeding. Critically ill patients are at higher risk of acute renal failure; at ICU admission, nearly one-third of patients have a creatinine clearance below $30 \mathrm{ml} /$ minute [9]. This reduced renal clearance of
LMWH has led to recommendations to monitor LMWH blood levels in patients with severe renal insufficiency [68]. A first meta-analysis failed to demonstrate bioaccumulation of LMWH used as thromboprophylaxis in critically ill patients with renal insufficiency [69]. Two recent prospective observational studies have been performed: the first is a single-center cohort study enrolling 19 patients with a creatinine clearance of $30 \mathrm{ml} /$ minute or above at ICU admission, receiving 5,000 UI subcutaneous dalteparin daily [70]. The second study was a multicenter prospective cohort study of 138 ICU patients with an estimated creatinine clearance under $30 \mathrm{ml} /$ minute [58], and who received 5,000 UI subcutaneous dalteparin once daily for thromboprophylaxis. No bioaccumulation of LMWH occurred in both studies. Dalteparin has not been associated with bleeding in critically ill patients with severe renal insufficiency. However, the impact of LMWHs other than dalteparin is still controversial.

\section{Mechanical thromboprophylaxis in ICU patients}

When anticoagulant is contraindicated, mechanical thromboprophylaxis using either graduated compression stockings (GCS) or intermittent pneumatic compression (IPC) may be proposed. Thromboprophylaxis by mechanical means alone is recommended for critical care patients at high risk of bleeding with contraindications to prophylaxis with anticoagulant agents [35]. The main RCTs that include GCS or IPC for DVT prophylaxis in ICU patients are listed in Table 5 [71]; one was conducted in patients with acute myocardial infarction [72], and three others in trauma patients [73-75]. These four studies represent 791 patients who underwent mechanical prophylaxis (several methods were evaluated) or received LMWH. One study evaluated GCS on one leg versus nothing on the second leg in each patient; the incidence of DVT was lower with GCS (0 \% versus $10 \%$ ) [72]. Combining IPC with GCS was not more effective than GCS alone [76]. In neurosurgical patients, GCS

Table 5 Randomized clinical trials evaluating mechanical thromboprophylaxis in the ICU

\begin{tabular}{|c|c|c|c|c|c|c|}
\hline Author (year) & Population & $\begin{array}{l}\text { Number of } \\
\text { patients }\end{array}$ & Diagnosis method & Intervention & $\begin{array}{l}\text { DVT } \\
\text { incidence }\end{array}$ & $P$-value \\
\hline \multirow{2}{*}{$\begin{array}{l}\text { Kierkegaard and } \\
\text { Norgren } 1993 \text { [72] }\end{array}$} & \multirow{2}{*}{$\begin{array}{l}\text { Patients aged }>70 \text { years, } \\
\text { myocardial infarction }\end{array}$} & \multirow[t]{2}{*}{80} & \multirow{2}{*}{$\begin{array}{l}\text { I-labeled fibrinogen test } \\
\text { on alternate days }\end{array}$} & No GCS & $8(10 \%)$ & \multirow[t]{2}{*}{0.003} \\
\hline & & & & GCS & $0(0 \%)$ & \\
\hline \multirow[t]{2}{*}{ Elliott et al. 1999 [74] } & \multirow[t]{2}{*}{ Trauma patients } & \multirow[t]{2}{*}{149} & \multirow[t]{2}{*}{ CUS on day 8 or before } & Calf-thigh IPC & $4(6.5 \%)$ & \multirow[t]{2}{*}{0.009} \\
\hline & & & & Plantar venous IPC & $13(21 \%)$ & \\
\hline \multirow[t]{2}{*}{ Ginzburg et al. 2003 [75] } & \multirow[t]{2}{*}{ Trauma patients } & \multirow[t]{2}{*}{442} & \multirow{2}{*}{$\begin{array}{l}\text { CUS within } 24 \text { hours of } \\
\text { admission and weekly }\end{array}$} & IPC & $6(2.7 \%)$ & \multirow[t]{2}{*}{0.12} \\
\hline & & & & LMWH & $1(0.5 \%)$ & \\
\hline \multirow[t]{2}{*}{ Kurtoglu et al. 2004 [73] } & \multirow[t]{2}{*}{ Trauma patients } & \multirow[t]{2}{*}{120} & \multirow{2}{*}{$\begin{array}{l}\text { CUS on admission, weekly, and } \\
1 \text { week after discharge }\end{array}$} & IPC & $4(6.6 \%)$ & \multirow[t]{2}{*}{0.04} \\
\hline & & & & LMWH & $3(5 \%)$ & \\
\hline
\end{tabular}


alone prevented DVT less effectively than when combined with LMWH [77].

The use of vena cava filters for thromboprophylaxis is not recommended by the ACCP Evidence-Based Clinical Practice Guidelines (eighth edition) [35].

\section{Thromboprophylaxis compliance in the ICU}

The ENDORSE multinational study enrolled 68,183 hospitalized patients in an acute care setting and showed that only a low rate of patients had appropriate prophylaxis according to the 2004 ACCP guidelines on VTE prophylaxis. In an Asian ICU, a recent observational study revealed that $20 \%$ of the critically ill patients did not receive the appropriate recommended prophylaxis [78]. In North-American ICUs, Lauzier et al. [79] recently reported appropriate guideline concordance occurred for $95.5 \%$ patient-days, which was better in sicker patients and in patients with a previous history of VTE or cancer. LMWH was less used than UHF in sicker and surgical patients, and in patients receiving vasopressors or renal replacement therapy [79].

\section{What about asymptomatic pulmonary embolism?}

The prevalence of incidental emboli in in-patients varies from 0.6 to $5.7 \%$ [80]. In moderate to severe injured trauma patients, CT scans showed asymptomatic PE in $22(24 \%)$ patients, of which $30 \%$ were receiving thromboprophylaxis. Only four patients with a major clot, and one with a minor clot but with an associated DVT, were treated at therapeutic doses. None of the 10 patients with minor clot and no therapeutic anticoagulation therapy was associated with any complication attributable to thromboembolic disease within 3 months [13]. In our study of mechanically ventilated patients in the ICU, 33 of $176(18.7 \%)$ patients had a diagnosed PE; 20 of these were asymptomatic (60\%) [17]. All these patients were treated early with therapeutic anticoagulation whenever they had lobar, segmental or subsegmental PE. ICU and hospital mortality were not different between patients with and without diagnosed PE.

So what should we do for asymptomatic PE cases? Should we routinely look to detect all asymptomatic PE? Although it seems evident to treat all PE, regardless of their symptoms, once they are detected, should we treat all asymptomatic PE cases? Most unsuspected emboli found on CT scans are small and segmental or subsegmental [81] and their management is not clear. Patients with false negative undiagnosed PE on $\mathrm{CT}$ scan have favorable short-term outcome without therapeutic anticoagulation [82]. Eyer et al. [83] also demonstrated no attributable mortality with untreated subsegmental emboli. On the other hand, early diagnosis of PE and routine use of early therapeutic anticoagulation in symptomatic or asymptomatic PE contributed to a low rate of fatal PE [17].
These results seem to support the need for routinely looking for PE in patients receiving mechanical ventilation. Whether mortality would be higher if these asymptomatic $\mathrm{PE}$ cases are not treated remains to be evaluated.

\section{Conclusion}

Diagnosis and management of clinically silent PE in critically ill patients are challenging. Current diagnosis tools, such as CTPA, allow the efficient diagnosis of silent PE if carried out systematically in mechanically ventilated patients. Considering the high risk of VTE in ICU patients, including specific VTE risk factors like mechanical ventilation, vasopressor use and central venous catheter use, thromboprophylaxis is recommended. LMWH could be more effective than UFH for VTE prophylaxis in the ICU. However, the high risk of bleeding in many critically ill patients makes the benefit-risk ratio of thromboprophylaxis difficult to evaluate. Further research on the diagnosis of $\mathrm{PE}$ and on whether asymptomatic peripheral PE should be treated or not is needed.

\section{Abbreviations}

ACCP: American College of Chest Physicians; CT: computed tomography; CTPA: computed tomographic pulmonary angiography; CUS: compression ultrasonography; DVT: deep venous thrombosis; GCS: graduated compression stockings; IPC: intermittent pneumatic compression; LMWH: low molecular weight heparin; PE: pulmonary embolism; PESI: Pulmonary Embolism Severity Index; RCT: randomized controlled trial; sPESI: simplified Pulmonary Embolism Severity Index; TEE: transesophageal echocardiography; TTE: transthoracic echocardiography; UFH: unfractionated heparin; VTE: venous thromboembolism.

\section{Competing interests}

This work received no financial support. The authors declare that they have no competing interests.

\section{Acknowledgements}

The authors thank Céline Feger, MD (EMIBiotech) for her editorial assistance.

\section{Author details}

${ }^{1}$ UJF-Grenoble I, University Hospital Albert Michallon, Medical Intensive Care Unit, Grenoble F-38041, France. '2Department of Radiology, UJF-Grenoble I, University Hospital Albert Michallon, Grenoble F-38041, France.

${ }^{3}$ UJF-Grenoble I, University Hospital Albert Michallon, U823 Institut Albert Bonniot, Team 11: Outcome of mechanically ventilated patients and airway cancers, Grenoble F-38041, France.

Published online: 18 August 2015

\section{References}

1. Perkins GD, McAuley DF, Davies S, Gao F. Discrepancies between clinical and postmortem diagnoses in critically ill patients: an observational study. Crit Care. 2003;7:R129-32.

2. McLeod AG, Geerts W. Venous thromboembolism prophylaxis in critically ill patients. Crit Care Clin. 2011;27:765-80. v.

3. Konstantinides SV. 2014 ESC Guidelines on the diagnosis and management of acute pulmonary embolism. Eur Heart J. 2014;35:3145-6.

4. Moser KM, LeMoine JR, Nachtwey FJ, Spragg RG. Deep venous thrombosis and pulmonary embolism. Frequency in a respiratory intensive care unit. JAMA. 1981:246:1422-4.

5. Cade JF. High risk of the critically ill for venous thromboembolism. Crit Care Med. 1982;10:448-50.

6. Kapoor M, Kupfer YY, Tessler S. Subcutaneous heparin prophylaxis significantly reduces the incidence of venous thromboembolic events in the critically ill [abstract]. Crit Care Med. 1999;27:A69. 
7. Fraisse F, Holzapfel L, Couland JM, Simonneau G, Bedock B, Feissel M, et al. Nadroparin in the prevention of deep vein thrombosis in acute decompensated COPD. The Association of Non-University Affiliated Intensive Care Specialist Physicians of France. Am J Respir Crit Care Med. 2000;161:1109-14.

8. Cook D, Meade M, Guyatt G, Walter S, Heels-Ansdell D, Warkentin TE, et al. Dalteparin versus unfractionated heparin in critically ill patients. N Engl J Med. 2011;364:1305-14.

9. Cook D, Crowther M, Meade M, Rabbat C, Griffith L, Schiff D, et al. Deep venous thrombosis in medical-surgical critically ill patients: prevalence, incidence, and risk factors. Crit Care Med. 2005:33:1565-71.

10. Ibrahim EH, Iregui M, Prentice D, Sherman G, Kollef MH, Shannon W. Deep vein thrombosis during prolonged mechanical ventilation despite prophylaxis. Crit Care Med. 2002;30:771-4.

11. Harris LM, Curl GR, Booth FV, Hassett Jr JM, Leney G, Ricotta JJ. Screening for asymptomatic deep vein thrombosis in surgical intensive care patients. J Vasc Surg. 1997;26:764-9.

12. Hirsch DR, Ingenito EP, Goldhaber SZ. Prevalence of deep venous thrombosis among patients in medical intensive care. JAMA. 1995;274:335-7.

13. Schultz DJ, Brasel KJ, Washington L, Goodman LR, Quickel RR, Lipchik RJ, et al. Incidence of asymptomatic pulmonary embolism in moderately to severely injured trauma patients. J Trauma. 2004;56:727-31. discussion 731-23.

14. Patel R, Cook DJ, Meade MO, Griffith LE, Mehta G, Rocker GM, et al. Burden of illness in venous thromboembolism in critical care: a multicenter observational study. J Crit Care. 2005;20:341-7.

15. Bahloul M, Chaari A, Kallel H, Abid L, Hamida CB, Dammak H, et al. Pulmonary embolism in intensive care unit: predictive factors, clinical manifestations and outcome. Ann Thorac Med. 2010;5:97-103.

16. Bahloul M, Chaari A, Dammak H, Medhioub F, Abid L, Ksibi H, et al. Posttraumatic pulmonary embolism in the intensive care unit. Ann Thorac Med. 2011;6:199-206.

17. Minet C, Lugosi M, Savoye PY, Menez C, Ruckly S, Bonadona A, et al. Pulmonary embolism in mechanically ventilated patients requiring computed tomography: Prevalence, risk factors, and outcome. Crit Care Med. 2012:40:3202-8

18. Goldhaber SZ, Visani L, De Rosa M. Acute pulmonary embolism: clinical outcomes in the International Cooperative Pulmonary Embolism Registry (ICOPER). Lancet. 1999;353:1386-9.

19. Torbicki A, Perrier A, Konstantinides S, Agnelli G, Galie N, Pruszczyk P, et al. Guidelines on the diagnosis and management of acute pulmonary embolism: the Task Force for the Diagnosis and Management of Acute Pulmonary Embolism of the European Society of Cardiology (ESC). Eur Heart J. 2008:29:2276-315.

20. Wells PS, Anderson DR, Rodger M, Forgie M, Kearon C, Dreyer J, et al. Evaluation of D-dimer in the diagnosis of suspected deep-vein thrombosis. N Engl J Med. 2003;349:1227-35.

21. Sathe PM, Patwa UD. D Dimer in acute care. Int J Crit IIIn Inj Sci. 2014;4:229-32.

22. Crowther MA, Cook DJ, Griffith LE, Devereaux PJ, Rabbat CC, Clarke FJ, et al. Deep venous thrombosis: clinically silent in the intensive care unit. J Crit Care. 2005;20:334-40.

23. Fraser JD, Anderson DR. Deep venous thrombosis: recent advances and optimal investigation with US. Radiology. 1999;211:9-24.

24. Birdwell BG, Raskob GE, Whitsett TL, Durica SS, Comp PC, George JN, et al. The clinical validity of normal compression ultrasonography in outpatients suspected of having deep venous thrombosis. Ann Intern Med. 1998;128:1-7.

25. Goldhaber SZ, Bounameaux H. Pulmonary embolism and deep vein thrombosis. Lancet. 2012;379:1835-46.

26. Kory PD, Pellecchia CM, Shiloh AL, Mayo PH, DiBello C, Koenig S. Accuracy of ultrasonography performed by critical care physicians for the diagnosis of DVT. Chest. 2011;139:538-42.

27. Quiroz R, Kucher N, Zou KH, Kipfmueller F, Costello P, Goldhaber SZ, et al. Clinical validity of a negative computed tomography scan in patients with suspected pulmonary embolism: a systematic review. JAMA. 2005;293:2012-7.

28. Patel S, Kazerooni EA, Cascade PN. Pulmonary embolism: optimization of small pulmonary artery visualization at multi-detector row CT. Radiology. 2003;227:455-60.

29. Remy-Jardin M, Pistolesi M, Goodman LR, Gefter WB, Gottschalk A, Mayo JR, et al. Management of suspected acute pulmonary embolism in the era of $C T$ angiography: a statement from the Fleischner Society. Radiology. 2007;245:315-29.

30. Kang DK, Thilo C, Schoepf UJ, Barraza Jr JM, Nance Jr JW, Bastarrika G, et al. $C T$ signs of right ventricular dysfunction: prognostic role in acute pulmonary embolism. JACC Cardiovasc Imaging. 2011;4:841-9.
31. Park JR, Chang SA, Jang SY, No HJ, Park SJ, Choi SH, et al. Evaluation of right ventricular dysfunction and prediction of clinical outcomes in acute pulmonary embolism by chest computed tomography: comparisons with echocardiography. Int J Cardiovasc Imaging. 2012;28:979-87.

32. Schwebel C, Clec'h C, Magne S, Minet C, Garrouste-Orgeas M, Bonadona A et al. Safety of intrahospital transport in ventilated critically ill patients: a multicenter cohort study. Crit Care Med. 2013;41:1919-28.

33. Miniati M, Monti S, Pratali L, Di Ricco G, Marini C, Formichi B, et al. Value of transthoracic echocardiography in the diagnosis of pulmonary embolism: results of a prospective study in unselected patients. Am J Med. 2001;110:528-35.

34. Pruszczyk P, Torbicki A, Pacho R, Chlebus M, Kuch-Wocial A, Pruszynski B, et al. Noninvasive diagnosis of suspected severe pulmonary embolism: transesophageal echocardiography vs spiral CT. Chest. 1997;112:722-8.

35. Geerts WH, Bergqvist D, Pineo GF, Heit JA, Samama CM, Lassen MR, et al. Prevention of venous thromboembolism: American College of Chest Physicians Evidence-Based Clinical Practice Guidelines (8th Edition). Chest. 2008:133:381S-453S

36. Darze ES, Latado AL, Guimaraes AG, Guedes RA, Santos AB, de Moura SS, et al. Incidence and clinical predictors of pulmonary embolism in severe heart failure patients admitted to a coronary care unit. Chest. 2005;128:2576-80

37. Shorr AF, Williams MD. Venous thromboembolism in critically ill patients. Observations from a randomized trial in sepsis. Thromb Haemost. 2009;101:139-44

38. Cook D, Attia J, Weaver B, McDonald E, Meade M, Crowther M. Venous thromboembolic disease: an observational study in medical-surgical intensive care unit patients. J Crit Care. 2000;15:127-32.

39. Timsit JF, Farkas JC, Boyer JM, Martin JB, Misset B, Renaud B, et al. Central vein catheter-related thrombosis in intensive care patients: incidence, risks factors, and relationship with catheter-related sepsis. Chest. 1998;114:207-13.

40. Merrer J, De Jonghe B, Golliot F, Lefrant JY, Raffy B, Barre E, et al. Complications of femoral and subclavian venous catheterization in critically ill patients: a randomized controlled trial. JAMA. 2001;286:700-7.

41. Chastre J, Cornud F, Bouchama A, Viau F, Benacerraf R, Gibert C. Thrombosis as a complication of pulmonary-artery catheterization via the internal jugular vein: prospective evaluation by phlebography. N Engl J Med. 1982;306:278-81.

42. Joynt GM, Kew J, Gomersall CD, Leung WY, Liu EK. Deep venous thrombosis caused by femoral venous catheters in critically ill adult patients. Chest. 2000;117:178-83.

43. Trottier SJ, Veremakis C, O'Brien J, Auer Al. Femoral deep vein thrombosis associated with central venous catheterization: results from a prospective, randomized trial. Crit Care Med. 1995:23:52-9.

44. Monreal M, Raventos A, Lerma R, Ruiz J, Lafoz E, Alastrue A, et al. Pulmonary embolism in patients with upper extremity DVT associated to venous central lines - a prospective study. Thromb Haemost. 1994;72:548-50.

45. Kooij JD, van der Zant FM, van Beek EJ, Reekers JA. Pulmonary embolism in deep venous thrombosis of the upper extremity: more often in catheterrelated thrombosis. Neth J Med. 1997:50:238-42.

46. Mai C, Hunt D. Upper-extremity deep venous thrombosis: a review. Am J Med. 2011:124:402-7.

47. Lechner D, Wiener C, Weltermann A, Eischer L, Eichinger S, Kyrle PA. Comparison between idiopathic deep vein thrombosis of the upper and lower extremity regarding risk factors and recurrence. J Thromb Haemost. 2008;6:1269-74.

48. Munoz FJ, Mismetti P, Poggio R, Valle R, Barron M, Guil M, et al. Clinical outcome of patients with upper-extremity deep vein thrombosis: results from the RIETE Registry. Chest. 2008;133:143-8.

49. Raad II, Luna M, Khalil SA, Costerton JW, Lam C, Bodey GP. The relationship between the thrombotic and infectious complications of central venous catheters. JAMA. 1994;271:1014-6.

50. Dorffler-Melly J, de Jonge E, Pont AC, Meijers J, Vroom MB, Buller HR, et al. Bioavailability of subcutaneous low-molecular-weight heparin to patients on vasopressors. Lancet. 2002;359:849-50.

51. Katz JN, Kolappa KP, Becker RC. Beyond thrombosis: the versatile platelet in critical illness. Chest 2011:139:658-68.

52. Selby R, Geerts W. Prevention of venous thromboembolism: consensus, controversies, and challenges. Hematology Am Soc Hematol Educ Program. 2009;286-92.

53. Collins R, Scrimgeour A, Yusuf S, Peto R. Reduction in fatal pulmonary embolism and venous thrombosis by perioperative administration of 
subcutaneous heparin. Overview of results of randomized trials in general, orthopedic, and urologic surgery. N Engl J Med. 1988;318:1162-73.

54. Mismetti P, Laporte-Simitsidis S, Tardy B, Cucherat M, Buchmuller A, JuillardDelsart $D$, et al. Prevention of venous thromboembolism in internal medicine with unfractionated or low-molecular-weight heparins: a metaanalysis of randomised clinical trials. Thromb Haemost. 2000;83:14-9.

55. Kearon C, Akl EA, Comerota AJ, Prandoni P, Bounameaux H, Goldhaber SZ, et al. Antithrombotic therapy for VTE disease: Antithrombotic Therapy and Prevention of Thrombosis, 9th ed: American College of Chest Physicians Evidence-Based Clinical Practice Guidelines. Chest. 2012;141:e419S-94S.

56. Ho KM, Chavan S, Pilcher D. Omission of early thromboprophylaxis and mortality in critically ill patients: a multicenter registry study. Chest. 2011;140:1436-46

57. Arnold DM, Donahoe L, Clarke FJ, Tkaczyk AJ, Heels-Ansdell D, Zytaruk N, et al. Bleeding during critical illness: a prospective cohort study using a new measurement tool. Clin Invest Med. 2007;30:E93-102.

58. Cook D, Douketis J, Meade M, Guyatt G, Zytaruk N, Granton J, et al. Venous thromboembolism and bleeding in critically ill patients with severe rena insufficiency receiving dalteparin thromboprophylaxis: prevalence, incidence and risk factors. Crit Care. 2008;12:R32.

59. Mismetti P, Laporte S, Darmon JY, Buchmuller A, Decousus H. Meta-analysis of low molecular weight heparin in the prevention of venous thromboembolism in general surgery. Br J Surg. 2001;88:913-30.

60. Harenberg J, Roebruck P, Heene DL. Subcutaneous low-molecular-weight heparin versus standard heparin and the prevention of thromboembolism in medical inpatients. The Heparin Study in Internal Medicine Group. Haemostasis. 1996:26:127-39.

61. Geerts WH, Jay RM, Code KI, Chen E, Szalai JP, Saibil EA, et al. A comparison of low-dose heparin with low-molecular-weight heparin as prophylaxis against venous thromboembolism after major trauma. N Engl J Med. 1996;336:701-7.

62. Kleber FX, Witt C, Vogel G, Koppenhagen K, Schomaker U, Flosbach CW. Randomized comparison of enoxaparin with unfractionated heparin for the prevention of venous thromboembolism in medical patients with heart failure or severe respiratory disease. Am Heart J. 2003;145:614-21.

63. Alhazzani W, Lim W, Jaeschke RZ, Murad MH, Cade J, Cook DJ. Heparin thromboprophylaxis in medical-surgical critically ill patients: a systematic review and meta-analysis of randomized trials. Crit Care Med. 2013;41:2088-98.

64. Haas CE, Nelsen JL, Raghavendran K, Mihalko W, Beres J, Ma Q, et al. Pharmacokinetics and pharmacodynamics of enoxaparin in multiple trauma patients. J Trauma. 2005;59:1336-43. discussion 1343-4.

65. Priglinger U, Delle Karth G, Geppert A, Joukhadar C, Graf S, Berger R, et al. Prophylactic anticoagulation with enoxaparin: is the subcutaneous route appropriate in the critically ill? Crit Care Med. 2003;31:1405-9.

66. Robinson S, Zincuk A, Strom T, Larsen TB, Rasmussen B, Toft P. Enoxaparin, effective dosage for intensive care patients: double-blinded, randomised clinical trial. Crit Care. 2010;14:R41.

67. Mayr AJ, Dunser M, Jochberger S, Fries D, Klingler A, Joannidis M, et al. Antifactor Xa activity in intensive care patients receiving thromboembolic prophylaxis with standard doses of enoxaparin. Thromb Res. 2002;105:201-4.

68. Weitz Jl. Low-molecular-weight heparins. N Engl J Med. 1997;337:688-98.

69. Lim W, Dentali F, Eikelboom JW, Crowther MA. Meta-analysis: lowmolecular-weight heparin and bleeding in patients with severe renal insufficiency. Ann Intern Med. 2006;144:673-84.

70. Rabbat CG, Cook DJ, Crowther MA, McDonald E, Clarke F, Meade MO, et al. Dalteparin thromboprophylaxis for critically ill medical-surgical patients with renal insufficiency. J Crit Care. 2005;20:357-63.

71. Limpus A, Chaboyer W, McDonald E, Thalib L. Mechanical thromboprophylaxis in critically ill patients: a systematic review and meta-analysis. Am J Crit Care. 2006;15:402-10. quiz/discussion, 411-2

72. Kierkegaard A, Norgren L. Graduated compression stockings in the prevention of deep vein thrombosis in patients with acute myocardial infarction. Eur Heart J. 1993;14:1365-8.

73. Kurtoglu M, Yanar H, Bilsel Y, Guloglu R, Kizilirmak S, Buyukkurt D, et al. Venous thromboembolism prophylaxis after head and spinal trauma: intermittent pneumatic compression devices versus low molecular weight heparin. World J Surg. 2004;28:807-11.

74. Elliott CG, Dudney TM, Egger M, Orme JF, Clemmer TP, Horn SD, et al. Calf-thigh sequential pneumatic compression compared with plantar venous pneumatic compression to prevent deep-vein thrombosis after non-lower extremity trauma. J Trauma. 1999;47:25-32.
75. Ginzburg E, Cohn SM, Lopez J, Jackowski J, Brown M, Hameed SM Randomized clinical trial of intermittent pneumatic compression and low molecular weight heparin in trauma. Br J Surg. 2003;90:1338-44.

76. Vignon P, Dequin PF, Renault A, Mathonnet A, Paleiron N, Imbert A, et al. Intermittent pneumatic compression to prevent venous thromboembolism in patients with high risk of bleeding hospitalized in intensive care units: the CIREA1 randomized trial. Intensive Care Med. 2013;39:872-80.

77. Agnelli G, Piovella F, Buoncristiani P, Severi P, Pini M, D'Angelo A, et al. Enoxaparin plus compression stockings compared with compression stockings alone in the prevention of venous thromboembolism after elective neurosurgery. N Engl J Med. 1998;339:80-5.

78. Parikh KC, Oh D, Sittipunt C, Kalim H, Ullah S, Aggarwal SK. Venous thromboembolism prophylaxis in medical ICU patients in Asia (VOICE Asia): a multicenter, observational, cross-sectional study. Thromb Res. 2012;129:e152-8.

79. Lauzier F, Muscedere J, Deland E, Kutsogiannis DJ, Jacka M, Heels-Ansdell D, et al. Thromboprophylaxis patterns and determinants in critically ill patients: a multicenter audit. Crit Care. 2014;18:R82.

80. Desai SR. Unsuspected pulmonary embolism on CT scanning: yet another headache for clinicians? Thorax. 2007;62:470-2.

81. Ritchie G, McGurk S, McCreath C, Graham C, Murchison JT. Prospective evaluation of unsuspected pulmonary embolism on contrast enhanced multidetector CT (MDCT) scanning. Thorax. 2007;62:536-40.

82. Engelke C, Rummeny EJ, Marten K. Pulmonary embolism at multi-detector row CT of chest: one-year survival of treated and untreated patients. Radiology. 2006;239:563-75.

83. Eyer BA, Goodman LR, Washington L. Clinicians' response to radiologists' reports of isolated subsegmental pulmonary embolism or inconclusive interpretation of pulmonary embolism using MDCT. AJR Am J Roentgenol. 2005;184:623-8. 